\title{
Tramas do Cotidiano: A Psicodinâmica do Trabalho em um Conselho Tutelar ${ }^{1}$
}

\author{
Dayly Script: \\ Labor Psychodynamics in a Child Protection Agency \\ Tramas del Cotidiano: \\ La Psicodinámica del Trabajo en un Consejo Tutelar
}

Norida Teotônio de Castro,

Ana Helena

Fernandes Toledo \&

Ana Maria Nunes Andery

Universidade do

Vale do Sapucaí
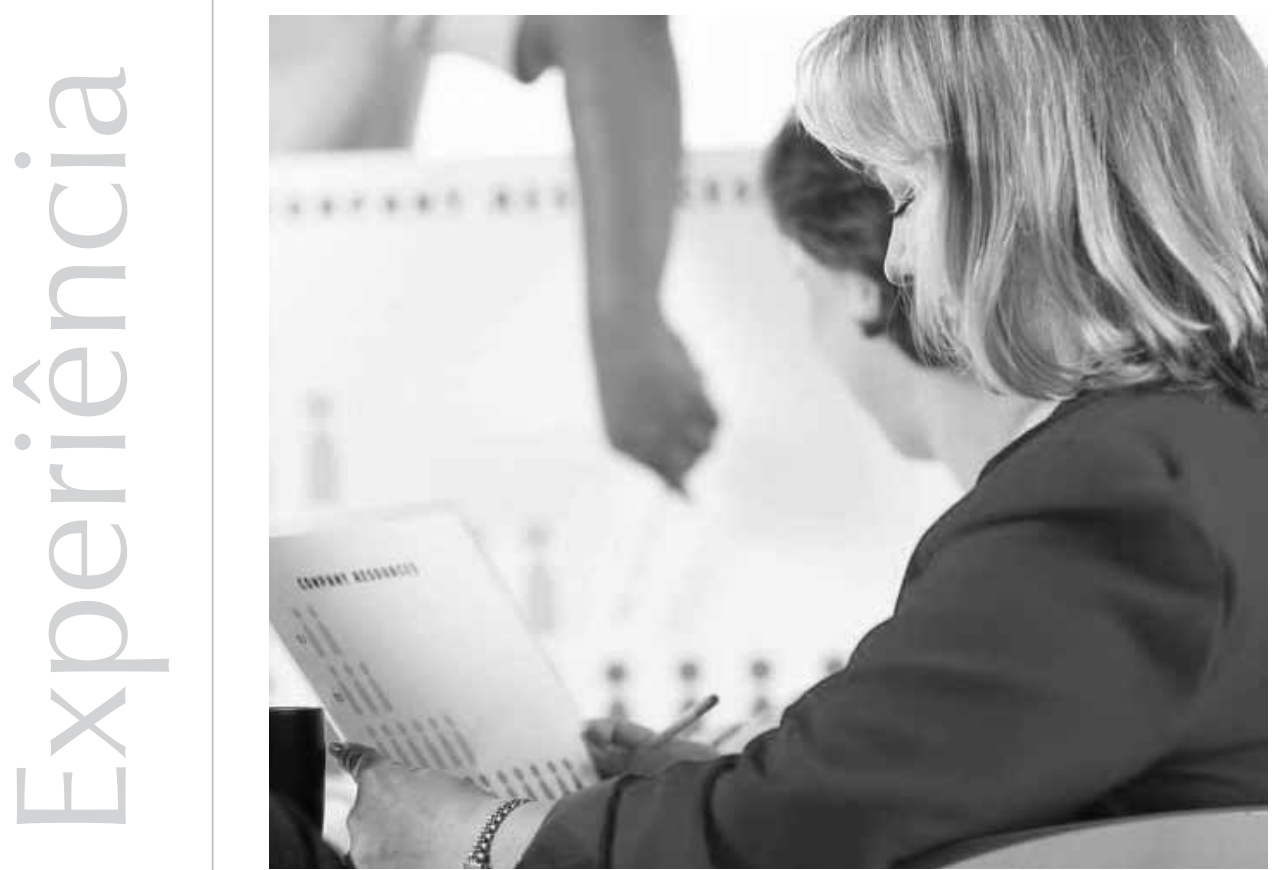
Resumo: O trabalho relata uma experiência de Estágio Supervisionado em Psicodinâmica do Trabalho, realizada com cinco integrantes de uma unidade do Conselho Tutelar de uma cidade do sul de Minas Gerais, em 2007. A intervenção objetivou propiciar melhores condições de trabalho às conselheiras e capacitar profissionalmente estudantes do quinto ano de um curso de Psicologia da região. Utilizou-se o método clínico para a compreensão dos eventos em campo: o triângulo da clínica do trabalho orientou o diagnóstico e a condução do processo terapêutico. Realizaram-se 17 encontros semanais, nos quais as conselheiras apresentaram, discutiram e tentaram encontrar soluções para as principais dificuldades individuais e coletivas do trabalho cotidiano. Os principais fatores indicados como fonte de sofrimento foram: as condições da estrutura física do ambiente de trabalho e as interações sociais entre as componentes da própria equipe e com outros agentes sociais. O sofrimento foi relativamente superado por meio de negociações internas e de um pacto coletivo de enfrentamento dos problemas inerentes à condução de casos atendidos e à interação com outros atores sociais. A intervenção contribuiu, sobretudo, com um espaço de relativa confiança, onde as conselheiras puderam se expressar, refletir e buscar soluções individuais e conjuntas para encarar e superar os elementos relacionados à realidade do trabalho.

Palavras-chave: Interações sociais. Psicanálise. Psicodinâmica do trabalho. Conselho Tutelar.

Abstract: This work reports a Supervised Training in Labor Psychodynamics case that took place in a Child Protection Agency, with its five agents, in the southern of Minas Gerais, in 2007. The intervention had as its main goal the set up of better work conditions and the improvement of the Psychology fifth year students professional education. It used the clinical method of labor psychodynamics triangle, that directed the diagnosis and the therapeutic processes. There were 17 weekly sessions, in which the agents showed, discussed and tried do find solutions to overcome the main daily individual and group difficulties. The main factors that aroused suffering were: material structure conditions in the work environment and social interactions among the agents and among the agents and other social actors. The suffering was partially overcome through agreements that took place within the group of workers, so they could better face the difficulties related to case conducts and to other social actors' interactions. The intervention has mainly contributed to create a confidence space, where the agents could discuss, think and look for group and individual responses to overcome the elements related to the reality of work.

Keywords: Social interaction. Psychoanalysis. Labor psychodynamics. Child Protection Agency.

Resumen: El trabajo relata una experiencia de Práctica Supervisada en Psicodinámica del Trabajo realizada con cinco integrantes de una unidad del Consejo Tutelar de una ciudad del Sur del Estado de Minas Gerais, en 2007. La intervención tuvo por objetivo propiciar mejores condiciones de trabajo a las consejeras y capacitar profesionalmente a estudiantes del quinto año de un Curso de Psicología de la región. Se utilizó el método clínico para la comprensión de los eventos en campo: el triángulo de la clínica del trabajo orientó el diagnóstico y la conducción del proceso terapéutico. Se realizaron 17 encuentros semanales, en los cuales las consejeras presentaron, discutieron y trataron de encontrar soluciones para las principales dificultades individuales y colectivas del trabajo cotidiano. Los principales factores indicados como fuente de sufrimiento fueron: las condiciones de la estructura física del ambiente de trabajo y las interacciones sociales entre las componentes del propio equipo y con otros agentes sociales. El sufrimiento fue relativamente superado por medio de negociaciones internas y pacto colectivo de enfrentamiento de los problemas inherentes a la conducción de casos atendidos y a la interacción con otros actores sociales. La intervención contribuyó, sobre todo con un espacio de relativa confianza, donde las consejeras pudieron expresarse, reflexionar y buscar soluciones individuales y conjuntas para encarar y superar los elementos relacionados a la realidad del trabajo.
1 as autoras esclarecem que as conselheiras tiveram acesso a uma cópia deste documento e, após tomar ciência de seu conteúdo, consentiram que ele fosse publicado. Agradecemos-lhes a oportunidade de conhecer, aprender, compartilhar

e, sobretudo, a generosidade em anuir à publicação do trabalho.
Este trabalho buscou apresentar uma experiência de estágio realizada por estudantes do quinto ano de um curso de Psicologia com membros do Conselho Tutelar de uma cidade do interior de Minas Gerais. A prática efetuada no Estágio Supervisionado em Psicodinâmica do Trabalho teve duplo objetivo: por um lado, propiciar melhores condições de trabalho às conselheiras; por outro, oportunizar a aprendizagem da clínica do trabalho e favorecer a formação profissional dos estudantes do Curso de Psicologia da Universidade do Vale do Sapucaí. Incluem-se nos primeiros objetivos: facilitar a expressão e a reflexão das conselheiras a respeito das vivências e das percepções acerca das próprias atividades e situações de trabalho, favorecer a autoavaliação na operacionalização das 
atividades e das relações estabelecidas, bem como propiciar a criação de estratégias para reduzir o esforço e adquirir melhor desempenho.

O Conselho Tutelar é um órgão público, autônomo, criado pelo Estatuto da Criança e do Adolescente (ECA), mediante a Lei Federal no 8069, de 13 de julho de 1990, para ser uma instância de representação da sociedade civil, que atua na defesa dos direitos fundamentais da criança e do adolescente quando estes são violados. É estruturado no Município, composto por cinco participantes (conselheiros) eleitos por voto direto, para mandato de três anos, podendo ocorrer somente uma reeleição consecutiva. O candidato a conselheiro deve morar no Município de atuação, ter idade mínima de 21 anos e atestar idoneidade moral (Prefeitura Municipal de Santos, Secretaria de Ação Comunitária e Cidadania, 1990).

O Conselho Tutelar (CT) tem como função atender reclamações e denúncias referentes a quaisquer irregularidades de atendimento ou ausência de atendimento que violem os direitos da criança e do adolescente. Situações de abandono, negligência, exploração, violência, crueldade e discriminação de meninos e meninas acontecidas no Município devem ser encaminhadas àquele órgão (Sêda, 1993), cuja função não é atender, e sim, encaminhar. Por isso, sua atuação tem caráter de escuta, orientação, aconselhamento e encaminhamento. Cabe também ao CT fiscalizar os serviços que o Município oferece e verificar se os direitos das crianças e adolescentes estão sendo garantidos (Andrade \& Novo, 2004). Além disso, os conselheiros devem sugerir e reivindicar políticas públicas de proteção infanto-juvenil, porém deve ficar evidente que a criação de novas políticas públicas ou as alterações de políticas existentes é de responsabilidade do
Conselho Municipal de Direitos da Infância e da Adolescência (CMDIA, Santos, 1999).

O levantamento bibliográfico a respeito dos CTs realizado no SciELO Brasil, em março de 2009, indicou escassez de estudos relativos ao assunto. Loureiro e Milani (2008), em artigo em que analisaram as medidas de proteção aplicadas pelo CT de Maringá às famílias que notificaram violência doméstica, identificaram na literatura nacional recente somente quatro trabalhos: dois se referiam às relações entre CT e escola (Parré, 2005; Souza, Teixeira, \& Silva, 2003), e os demais tratavam das concepções e práticas vigentes no órgão (Castro, 2002; Peres, 2001). Em recente busca de literatura realizada para este trabalho, em fevereiro de 2009, encontraram-se mais estudos, porém nenhum relatou pesquisa ou intervenção que relacionasse psicodinâmica do trabalho e Conselho Tutelar.

A síntese da literatura estudada revelou os seguintes aspectos no que se refere à prática do conselheiro tutelar: amplitude e variedade do campo de atuação, multiplicidade de interação com diferentes atores sociais, exigência de clareza e discernimento necessários para encaminhamentos adequados, prontidão (adequação e rapidez) para responder a situações, principalmente as de urgência, mobilização de pontos adequados da rede social de apoio, visibilidade social e exposição a críticas e enfrentamento de situações que provocam tensão e forte mobilização emocional. Depoimentos de representantes dos setores envolvidos em ações relacionadas ao ECA conferem importância ao papel social do CT, mas dirigem suas críticas especialmente aos conselheiros, afirmando que, apesar de demonstrarem vontade, são pouco qualificados. Queixam-se, ainda, da falta de retorno e de soluções para os casos encaminhados, embora haja reconhecimento de que o trabalho "exige muito" e precisa ser valorizado. Além disso, as conclusões dos estudos atrelaram a qualidade dos serviços 
à formação profissional do conselheiro (Loureiro \& Milani, 2008).

A criação dos CTs inaugurou uma nova modalidade de trabalho, a do conselheiro tutelar, que merece especial atenção. $\mathrm{O}$ levantamento bibliográfico realizado até o momento não revelou relato algum de experiência de acompanhamento psicológico com equipes de conselheiros tutelares, tampouco apresentou investigações relativas à subjetividade do conselheiro como trabalhador.

Importa acrescentar que o relato de uma pesquisa-intervenção realizada com os membros de um CT pode ampliar e aprofundar o conhecimento a respeito da natureza, da qualidade e dos efeitos dos intercâmbios com outros órgãos e atores sociais, além de elucidar aspectos de seu funcionamento interno, isto é, os meandros das vivências cotidianas do conselheiro com seus modos operatórios, associandoos às principais problemáticas enfrentadas. Ademais, a circulação do relato de uma prática profissional pode contribuir para se vislumbrar possibilidades de outros estudos e intervenções no mesmo setor, ampliando o campo de atuação do psicólogo e de formação do estudante de Psicologia, e ainda para propiciar críticas e suscitar possíveis alternativas favoráveis ao desenvolvimento profissional do psicólogo.

\section{A intervenção: aspectos metodológicos}

\section{As condições da intervenção}

A intervenção psicológica foi realizada por duas estagiárias acadêmicas do último ano do Curso de Psicologia, sob a supervisão de uma docente responsável, durante um ano letivo. A intervenção ocorreu mediante solicitação das conselheiras por atendimento psicológico, com a justificativa de que "o trabalho no Conselho Tutelar é árduo e estressante, muitas vezes causando grandes frustrações diante do triste quadro com que convivem diariamente".

No início do atendimento, o CT havia se mudado recentemente para uma casa alugada pela prefeitura, onde eram realizados outros serviços públicos. O novo espaço consistia de cozinha, banheiro, sala de espera e três salas de atendimento. O CT funcionava das 8 às 17 horas, e as conselheiras se organizavam em turnos de seis horas diárias e em regime de plantão, para o qual estabeleceram um sistema de rodízio. Os casos eram atendidos, geralmente, por um único conselheiro responsável pelos encaminhamentos ou em parceria, principalmente quando havia ocorrências no horário de plantão ou nas férias de algum conselheiro.

O quadro de pessoal, além das cinco conselheiras, contava com um auxiliar de limpeza e um atendente que exercia múltiplas funções (porteiro, secretário, etc.). Das cinco conselheiras eleitas, duas haviam participado da gestão anterior, e as demais exerciam seu primeiro mandato. Essas cinco conselheiras tomaram parte na intervenção, cada uma designada com uma letra, para proteção do anonimato.

\section{O referencial teórico utilizado}

A psicodinâmica do trabalho é uma disciplina que busca compreender os aspectos psíquicos e subjetivos que são mobilizados com base na organização e nas relações estabelecidas no ambiente de trabalho. Visa a estudar as dimensões menos visíveis da experiência de trabalho, como mecanismos de cooperação, reconhecimento, sofrimento, mobilização da inteligência, vontade e motivação, estratégias defensivas criadas e estabelecidas bem como os processos identificatórios forjados nas vivências laborais. Utiliza metodologia específica, denominada clínica do trabalho, 
que liga intervenção e pesquisa e que permite compreender os processos psíquicos envolvidos. Não busca transformar o trabalho, e, sim, o trabalhador (Heloani \& Lancman, 2004).

A clínica do trabalho é uma proposta subsidiada teoricamente na psicanálise, e leva em consideração três termos básicos: o sujeito, o trabalho e o outro. Deve-se atentar para a dimensão reguladora existente entre os três termos. Assim, o elemento sujeito envolve identidade, processos identificatórios, nível de interesse e tensão psíquica, e está relacionado à dialética sofrimento/prazer, vividos pelo sujeito no seu cotidiano de trabalho. O termo real do trabalho diz respeito a todo e qualquer aspecto do trabalho e à operacionalização de tarefas que oferecem resistência à ação do trabalhador, tais como: panes, incidentes inesperados, incoerência organizacional, transtornos na operação de máquinas e materiais, dificuldades na interação com chefes, colegas, subordinados, etc. (Dejours, 2004d). Já o elemento outro corresponde à esfera social que se apresenta em termos de prestígio, lucro, remuneração, e que está vinculada ao reconhecimento do trabalho, isto é, ao valor conferido ou negado ao trabalhador.

A alienação mental foi a preocupação inicial de Dejours, quando se dedicava à psicopatologia do trabalho, e o autor estabeleceu nexos de causalidade entre os elementos existentes na situação de trabalho e o adoecimento psíquico (alienação mental). Posteriormente, subverteu a lógica da causalidade em favor da lógica da psicodinâmica, quando, em situações propensas ao adoecimento, encontrou pessoas que conseguiam criar mecanismos subjetivos (individuais ou coletivos) pelos quais conseguiam "escapar" de um "esperado transtorno psíquico". Entretanto, nem todos são capazes de se livrar desse transtorno, porque o adoecimento pode acontecer por causa de uma retenção da energia pulsional, gerada em uma situação de trabalho que impede a descarga adequada da carga psíquica (Brant \& Gomes, 2004).

Assim, em determinada situação de trabalho, vale questionar: como se encontra o sujeito, ou o coletivo em questão? Essa pergunta é crucial para o diagnóstico e o direcionamento adequado de uma intervenção. Há três possibilidades de vivência subjetiva de trabalho, individual ou coletiva, levando-se em consideração os três termos:

a) a alienação mental: quando ocorre simultaneamente perda de contato com a realidade e ausência de reconhecimento pelo outro. Há, nesse caso, ruptura dos laços sociais e da relação com a realidade de trabalho que poderia atuar como referência subjetiva. Trata-se da condição de "solidão da loucura clássica", segundo Dejours (2004b, p. 98).

b) a alienação social: quando o sujeito estabelece relação com a realidade do trabalho, mas não obtém reconhecimento pelo outro. São exemplos ilustrativos dessa situação: o gênio não reconhecido e as situações perversas em que se nega a contribuição ou o valor do trabalhador. Nessas circunstâncias, o sujeito pode apresentar perda de autoconfiança e manifestar um quadro depressivo caso não construa mecanismos para se proteger.

c) alienação cultural: o sujeito tem o reconhecimento do outro, mas o seu vínculo com a realidade está rompido, sem contato com a realidade. Caracterizam tal situação: os resultados ruins, as falhas e a má qualidade no produto final (sintoma - sinal de que algo não vai bem). São exemplos dessa situação: os modos operatórios idealizados das seitas, políticos que perderam contato com suas bases ou desconhecem suas necessidades, casos de fraudes, tarefas realizadas aos trancos e barrancos e produtos defeituosos, dentre outros (Dejours, 2004b, p. 99). 


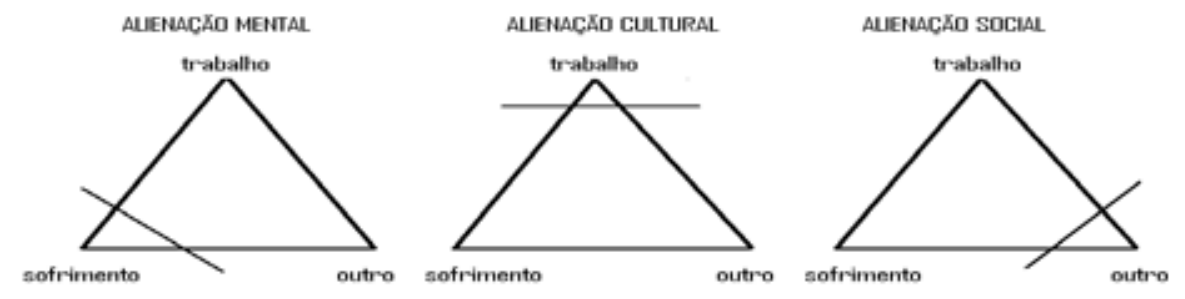

Figura 1.Triângulo da clínica do trabalho com a representação dos tipos de alienação: mental, cultural e social (Fonte: Dejours, 2004a, pp. 208-209).

A posição subjetiva pode ser retratada em uma das variações do triângulo. Como isso pode ser realizado? Mediante a fala e a escuta do trabalhador. Quando o trabalhador se refere a seu trabalho, fala sempre de uma vivência subjetiva relacionada aos outros dois termos indicados: a real do trabalho e o reconhecimento de natureza social.

Para Brant e Gomes (2004), o mérito de Dejours foi conceber a fala do trabalhador como um instrumento de pesquisa e de intervenção. Se o trabalhador for capaz de elaborar a experiência do trabalho ao falar, se for capaz de simbolizar e de chegar a uma interpretação, terá a possibilidade de fazer evoluir a organização do trabalho; portanto, a criação de um espaço de expressão compartilhado favorece o exercício da reflexão individual e coletiva. Vivências que passariam despercebidas ou gerariam sensações difusas ganham sentido ao serem verbalizadas e discutidas, e proporcionam compreensão mútua, além evidenciarem a racionalidade e o sentido do trabalho, fenômeno esse denominado inteligibilidade (Heloani \& Lancman, 2004).

\section{O espaço de interlocução}

A intervenção adotou os procedimentos propostos pela clínica do trabalho, utilizando a técnica da pesquisa-ação e os grupos de discussão a respeito das situações de trabalho. O espaço de interlocução, propício à reflexão, à expressão de sentimentos e à elaboração das vivências de trabalho/fonte de sofrimento, é favorável à criação de soluções, de mecanismos facilitadores e de recursos subjetivos de manejo e de enfrentamento de situações experienciadas.

\section{O processo da intervenção}

No início do ano letivo, procedeu-se ao contato com as conselheiras a fim de confirmar o interesse manifestado anteriormente. Apesar da resposta afirmativa, o início da intervenção ocorreu somente em maio, em virtude do atraso na mudança de endereço do CT.

No primeiro encontro com as conselheiras, as estagiárias esclareceram os objetivos da clínica do trabalho e expuseram os princípios do enquadramento para a realização dos atendimentos: o trabalho seria realizado mediante verbalização e discussão em espaço coletivo com a presença de todas as conselheiras, sendo toleradas as ausências somente em caso de folgas compensatórias de horas extras, ou férias, a conselheira ausente teria acesso, caso desejasse, mediante relato 
${ }^{2}$ Bleger (1984, pp. 46-47) descreve a utilização do método clínico: primeiramente, $\mathrm{o}$ enquadramento do próprio interventor, mediante a dissociação instrumental, em seguida, a indagação operativa,

realizada em quatro momentos: observação de todos os acontecimentos e de seus detalhes, com a continuidade ou sucessão em que os mesmos se dão; compreensão dos significados dos acontecimentos $\mathrm{e}$ da forma como eles se relacionam ou se integram; "inclusão dos resultados

da compreensão, no momento oportuno, em forma de interpretação, assinalamento ou reflexão;

consideração do passo anterior como uma hipótese que, ao ser emitida, inclui-se como uma nova variável". A descrição acima, embora oriunda de autor da Psicologia institucional, não conflita com a metodologia sugerida por Dejours. em situação grupal, ao conteúdo exposto durante sua falta, os encontros se realizariam semanalmente, salvo feriados e período de férias escolares, com duração aproximada de uma hora e trinta minutos, haveria o compromisso de sigilo com relação aos assuntos comentados no espaço de intervenção e supervisão, e a intervenção, iniciada em maio, terminaria em novembro.

As estagiárias foram orientadas a pautar suas ações segundo o método clínico (Dejours, 2004b; Bleger, 1984)², o exercício da escuta flutuante e a associação livre. As verbalizações expressas pelas estagiárias, em forma de pontuação, pergunta, reflexão, confrontação e/ou interpretação, seriam ancoradas no referencial teórico da clínica do trabalho fundado na interação dialética dos três termos do triângulo, já referidos. Além disso, deveriam registrar detalhadamente os eventos ocorridos durante as sessões para serem relatados e discutidos em supervisão.

Foram realizados 17 encontros, cujas temáticas consensuais gravitaram em torno de três eixos: a) infraestrutura e organização do trabalho, b) intersubjetividade e coordenação de ações e c) a função da equipe interventora.

\section{Infraestrutura e organização do trabalho}

A organização do trabalho geralmente diz respeito a um modo de operar ou a procedimentos a serem executados pelo trabalhador, determinados e decididos em um âmbito hierarquicamente superior e em circunstâncias das quais o trabalhador/ executor não participa (Abrahão \& Torres, 2004). Esse modo operatório foi denominado trabalho prescrito por Dejours (1997). No caso do $\mathrm{CT}$, cabe ao próprio conselheiro tomar decisões e estabelecer suas próprias condutas e procedimentos, tendo como diretrizes gerais - mas não detalhadamente prescritas - aquelas estabelecidas para os CTs de modo geral. Assim, a organização do trabalho nesse serviço requer tomada de decisão no âmbito próprio ou articulação com agentes fora desse âmbito. Tal procedimento confere maior autonomia e flexibilidade ao conselheiro do que à maioria dos trabalhadores, pois the permite mais propriedade no manejo de aspectos singulares referendados no contexto social corrente, na articulação de ações entre as próprias conselheiras e entre outros atores sociais, de acordo com as características dos casos atendidos.

As pautas dominantes relativas à organização do trabalho que surgiram nos encontros podem ser assim resumidas: a) exposição do modo de organizar os trabalhos entre as próprias conselheiras, incluindo quadro de horários relativos ao seu expediente, especificando horário de almoço, plantões, folgas e férias e b) apresentação de aspectos problemáticos relacionados à infraestrutura e ao espaço de trabalho.

O primeiro ponto teve como principal objetivo familiarizar as estagiárias com o funcionamento do Conselho. O segundo aspecto diz respeito à peculiaridade da situação do $\mathrm{CT}$, quando a intervenção se iniciou. As conselheiras haviam solicitado a mudança de endereço, em virtude da interferência negativa do espaço físico na condução do cotidiano de trabalho. A fala de A, no primeiro encontro, ilustra o desconforto vivenciado: "o espaço físico anterior onde a gente se encontrava provocava um grande mal-estar, faltava privacidade... parecia que ia explodir uma bomba atômica no local, de tão insuportável".

Após mudança de endereço, houve demora de dois meses para se instalarem os equipamentos, o que provocou uma série de obstáculos no desenvolvimento das atividades e gerou irritação e desmobilização subjetiva. Tais pendências tiveram desdobramentos em várias dimensões, tais como inviabilidade na 
recepção de algumas denúncias, morosidade na condução dos casos em andamento, impossibilidade de redigir pareceres, malentendidos com agentes institucionais que solicitavam medidas do $\mathrm{CT}$, etc.

Questionadas a respeito do que poderia ser feito para superar a situação, responderam que, em casos emergenciais, utilizavam os próprios recursos. A mobilização subjetiva apresentada pela conselheira B., de dispor de equipamento próprio (carro) para efetivar o trabalho, foi desmobilizada, no caso, em decorrência do recebimento de uma multa por estacionar em local indevido, mas permitido a prestadores do serviço municipal. Esse fato também levou à reflexão acerca das atribuições e responsabilidades de cada um dos setores envolvidos no exercício da função do CT: "Também não quero mais utilizar o meu carro, pois houve um mal entendido em relação à zona azul. Fui fazer um favor e ainda acabei recebendo multa. Em vista disso, não estou mais chamando responsabilidade para mim" (B, segundo encontro).

A situação exposta evidencia o quanto um CT pode estar à mercê de fatores e de ações políticas de outros órgãos e ter suas atividades reduzidas ou paralisadas, mesmo que parcialmente. Assim, fica patente que aspectos organizacionais de outros setores públicos podem comprometer a atuação de conselheiros tutelares, à revelia da sua vontade ou do seu interesse.

Intersubjetividade e coordenação de ações

O primeiro encontro foi dominado pela exposição catártica do mal-estar existente entre as conselheiras, expresso mediante a polarização de crença ou descrença no grupo, encontrada nas respectivas falas: "Acredito no grupo porque eu sei que as pessoas mudam. Eu vejo a minha mudança e acredito que as outras pessoas possam mudar também". (A);
"Não acredito que... possamos mais formar um grupo" (B).

As primeiras verbalizações de sofrimento na situação de trabalho convergiram para as relações entre os membros da equipe, quando as conselheiras pontuaram a dificuldade de coordenar as ações individuais em um projeto de atuação coletiva: "Sinto dificuldade de pedir várias vezes para que se faça um trabalho. Pedir muitas vezes me deixa irritada... Sofro porque guardo coisas que acontecem. Fico remoendo. Já fiquei até doente" (E, primeiro encontro).

Indagadas a respeito de como chegaram àquela situação, começaram a buscar nexos causais que explicassem o mal-estar corrente: características pessoais, eventos e modos individuais de operar. Desse modo, eliciaram um processo de transição, no qual ocorreu a passagem sutil de um modo de funcionamento emocional e de uma compreensão difusa e parcial das relações estabelecidas para uma consciência mais clara e inteligível das interações vividas. Isso ocorreu timidamente no primeiro encontro e se intensificou nos seguintes. Essa mudança pode ser apreendida nas falas cujos conteúdos apresentam a natureza das relações (afetos, conflitos, rivalidade e amizade, confiança, individualismo $x$ cooperação, interdependência das ações) associadas à organização do trabalho, o que foi acompanhado de indicações e prescrições de condutas que poderiam mitigar o malestar, como, por exemplo: "as questões do trabalho não devem ser envolvidas com as diferenças pessoais, uma coisa não pode atrapalhar a outra" (B, segundo encontro); " $E$ importante selecionar, filtrar o que interessa, e o resto é só deletar, pois colocar lenha na fogueira é besteira" (A, terceiro encontro).

Um incidente relatado no quarto encontro catalisou o processo de mudança em andamento, quando o motivo fundamental 
na condução de um caso, interpretado como equivocado, foi atribuído à qualidade da relação entre as conselheiras. Consideraram que equívocos da parte de uma só conselheira poderiam ser estendidos a todas e se refletirem na imagem da gestão corrente, deixando o atual CT vulnerável aos olhos da sociedade. Além disso, discutiram como a visibilidade social do órgão $C T$ requer cuidado no modo de proceder de cada conselheira, porque, na perspectiva de outros agentes sociais, autoridades e usuários, o agir individual poderia ser entendido como ação conjunta do CT: "Uma falha nossa pode acabar com uma família. Temos que zelar pelo nome do Conselho. Nós não estamos trabalhando em parceria, como um grupo" (B, quarto encontro).

Tornou-se visível para as conselheiras o sintoma (sinal de que algo não vai bem) do trabalho apresentado pela equipe, a alienação cultural, isto é, o corte na eficácia do trabalho, segundo o triângulo da clínica do trabalho (ver Figura 1). A interpretação da ineficiência do trabalho, nesse caso, residiu na omissão de um dos procedimentos do protocolo a ser seguido, ou seja, da apuração dos fatos, como revela a transcrição de parte do processo comunicativo ocorrido no quarto encontro:

Estagiária: - Há procedimentos prescritos a serem seguidos? Quais os procedimentos a serem utilizados após receber uma denúncia? E: - Sim, há um procedimento determinado de que se deve em primeiro lugar ouvir as queixas, depois apurar os fatos e só depois fazer o encaminhamento.

Estagiária: - O que não correspondeu ao procedimento prescrito, no caso?

B - A conselheira $C$ não havia apurado a queixa, tendo feito o encaminhamento da denúncia para o local... sem ouvir o Sr. ..., o que acabou causando problemas para ele, que veio ao CT indignado quanto ao fato de não Ihe ter sido oferecido o direito de resposta.
Observou-se também a capacidade de esse coletivo conviver com traços contraditórios dos sujeitos singulares. Apesar da avaliação geral de que a conduta de uma conselheira estava equivocada, houve expressão de reconhecimento horizontal: a colega de trabalho identificada com um predicado de cunho negativo na equipe - individualista -, pôde também ser identificada com predicados valorizados, tais como prestativa, ágil, destemida. Esse procedimento revela uma forma de reconhecimento da parte das colegas, observada no depoimento de A, no quarto encontro: "Por estar dividindo a sala com D, estou aprendendo a conhecê-la melhor. Ela é prestativa, é prática, é ágil. Chega às vezes a ser destemida e correr riscos por estar sozinha".

A partir do episódio relatado, tornou-se patente a necessidade de coordenação das ações entre as conselheiras, o que desencadeou a criação de um pacto de trabalho fundado na percepção da interdependência das ações individuais. É essencial acrescentar que a existência de coordenação exige a cooperação dos trabalhadores envolvidos. Cooperação e coordenação implicam a "construção de relações de confiança entre os trabalhadores" (Dejours, 2004e). O movimento coletivo, no tocante à coordenação dos modos operatórios individuais, levou a se reordenar a organização do trabalho, começando pela denúncia da qualidade das comunicações veiculadas entre as conselheiras. A natureza e a maneira como alguns comentários eram verbalizados costumavam soar como intrusivos e hostis, dependendo também do humor de quem os recebia. As características da comunicação entre as conselheiras constituíram um dos pontos a serem trabalhados pelas estagiárias, oportunidade que ocorreu no sexto encontro:

C: - Entendi que precisamos funcionar como equipe, e que as decisões sobre os casos devem ser analisadas e discutidas por todas até chegarem a um consenso.

D: - As colegas, dependendo do seu 
estado de espírito, têm reações diferentes em relação às demais colegas. Em um momento fazem brincadeiras com excesso de liberdade e, em outros, se ofendem por pouca coisa.

Estagiária: - Qual é a sinalização para o outro entender até que ponto ele pode "entrar"? Qual seria a fronteira, o limite entre vocês?

A associação seguinte consistiu na rememoração de falas e diálogos sucedidos no âmbito do trabalho e que originaram sentimentos desagradáveis. O estado de humor suscitado frequentemente se prolongava para o ambiente doméstico, onde ficavam insuportáveis, ou desabafavam e faziam com que o familiar (o cônjuge, principalmente) se solidarizasse com ela(s), o que significava que, muitas vezes, as questões do trabalho se desdobravam na esfera da vida doméstica. Concluíram que deviam ser mais observadoras quanto ao modo de se dirigirem umas às outras, para evitar desgaste desnecessário.

O engajamento das conselheiras na discussão descrita ilustra bem o confronto com uma das dimensões da real do trabalho, a resistência que o outro impõe ao sujeito. Note-se que o confronto pode levar a dois caminhos: a) à vivência de fracasso, quando as condições em que o sujeito colocado à prova não consegue subsídios, sejam sociais, sejam próprios, para se fazer reconhecer, arranjo que gera sofrimento e que pode levar a um estado patológico, ou b) à superação e ao desenvolvimento da subjetividade, quando os recursos subjetivos disponíveis e as condições são favoráveis ao desenvolvimento (Dejours, 2004e).

As conselheiras tomaram o segundo caminho, o que exigiu, de um lado, renúncia no plano individual, mas que, por outro lado, promoveu um ganho no que diz respeito à economia psíquica, em virtude da redução das tensões e do esforço na realização das tarefas (Dejours, 2004e; Molinier, 2004).

Essa nova intersubjetividade fundada na cooperação e na busca por coordenação das tarefas, mesmo que oscilatória, permitiu às conselheiras inaugurar o espaço de intervenção para discutir e avaliar casos e ocorrências que se lhes apresentavam de difícil manejo: "Como nós não conseguimos resolver isto sozinhas, resolvemos trazer para o grupo, para fazermos com a ajuda de vocês". A partir de então, puderam se mobilizar na criação de recursos para tratar de outras dimensões intersubjetivas, agora referentes à relação entre o CT-usuários e o CT- agentes de outras instituições.

O empenho e o esforço das conselheiras no acompanhamento de certos casos durante meses podem finalizar em eventos frustrantes, que constituem fonte de sofrimento:

Estou especialmente triste hoje, em vista de um caso muito difícil que estou acompanhando. Cheguei a chorar, quando soube que um menor, a quem foram dadas muitas oportunidades e em quem todas as conselheiras estavam investindo muitos cuidados, havia, naquela madrugada, furtado dois celulares, uma bolsa e uma moto, justamente da família que o acolhera. Fica muito difícil evitar o envolvimento emocional. ( $E$, décimo sétimo encontro)

Algumas conselheiras relataram que frequentemente se defrontavam com dilemas oriundos da própria dificuldade em formular algum juízo que conduzisse a um encaminhamento. Tais dilemas, muitas vezes, prolongavam as etapas de acolhimento de queixas, denúncias e apuração dos fatos:

às vezes prolongo os atendimentos, não por não conseguir fazer o corte, mas por sentir a importância do atendimento e acreditar que alguns minutos a mais podem fazer diferença na vida da pessoa. Às vezes é difícil analisar os casos, os fatos com distanciamento e imparcialidade. (A, sexto encontro) 
É oportuno explicar que o prolongamento do atendimento é interpretado como uma inabilidade, sendo a realização do corte (finalização de entrevistas de acolhimento ou de apuração) uma habilidade a ser aprendida. Por outro lado, o prolongamento, seja da escuta, seja da apuração do caso, pode constituir uma estratégia individual utilizada para adiar o julgamento, quando a conselheira está com um dilema, em conflito, ou impactada pela circunstância do momento. A escuta prolongada é justificada também pela necessidade de proporcionar acolhimento adequado ao usuário, quando ele demonstra sofrimento intenso.

Discernimento na análise dos casos e cuidado na realização de encaminhamentos constitui ponto vital, porque, não raro, as denúncias e as queixas apresentam versões divergentes, truncadas e mesmo conflitantes. O CT é alvo de manipulação intencional e não intencional de partes envolvidas em conflitos familiares, ou institucionais. Além disso, representantes de outros setores sociais frequentemente pressionam as conselheiras para apressarem decisões quando o caso demanda estudo mais aprofundado. Chegam até a insistir na imposição de determinadas medidas, embora sejam legalmente injustificadas:

Mas que existe, por trás da pressa da assistente social, uma intenção de fazer com que tomemos a atitude que ela quer que seja tomada. Precisamos ter muito cuidado, porque, se fizermos o abrigo desta criança sem fazer uma análise detalhada da situação, corremos o risco de ver esta criança em família substituta no dia seguinte, e esta mãe pode perder a guarda do filho. Tudo que é feito pelas conselheiras, todas as nossas atitudes têm consequências muito sérias para as pessoas envolvidas... Não podemos ser ingênuas de sair fazendo... sem uma análise detalhada do caso. (B, quinto encontro)

Ocorrências como essa são rotineiras, por isso, as conselheiras enfrentam o desafio de elaborar e estabelecer um posicionamento - e de construir argumentos que o defendam - para cada uma das mais diversas circunstâncias com que se deparam. A compreensão e o discernimento das ocorrências exigem o mecanismo que Sato (2002) denominou "negociação nos processos de planejamento", definida como "processos discursivos através dos quais se barganha o controle sobre a organização do processo de trabalho", ao que se acrescenta: o processo de negociação com o agente alheio ao $\mathrm{CT}$ requer também negociação entre as conselheiras.

A necessidade de negociação facilitou a transformação da qualidade dos vínculos entre as conselheiras e ajudou a promover relações mais cooperativas, do contrário, as conselheiras, individualmente, e todo o CT estariam fragilizados para sustentar confrontos com agentes externos, quando necessário. Como as situações desafiadoras com outros atores sociais se repetem e se revestem das formas mais singulares, as conselheiras também se veem forçadas a realizar negociações entre si, a construir argumentos e a replanejar suas condutas com igual frequência. Saldo positivo, pois a pressão externa mobilizou a emergência de posturas mais cooperativas como estratégia de defesa, levando as conselheiras a um exercício de superação dos modos operatórios estabelecidos e desencadeando o uso da inteligência, para dominar a resistência do real do trabalho (Dejours, 2004e; Molinier, 2004).

No entanto, nem sempre a intersubjetividade conselheira/agente externo se mostra conflituosa. $\mathrm{O}$ atendimento à solicitação de mudança de casa endereçada ao juiz foi acolhido como uma forma de reconhecimento, como se observa na fala de D: "graças à interferência do juiz, que 
modificou para melhor a impressão que tinha das conselheiras, conseguimos alugar a casa para a nova sede do Conselho Tutelar" (segundo encontro).

O exercício laboral constitui uma oportunidade de que o sujeito dispõe para construir vínculos sociais favoráveis à vida e à saúde mental. Isso, entretanto, somente é passível de se alcançar sob a condição de o sujeito ou o coletivo de trabalho obterem reconhecimento e serem acolhidos pelo Outro (Dejours, 2004b; Lacan, 1999).

\section{A função da equipe interventora}

Houve resistência inicial de algumas conselheiras em participar dos encontros, motivadas pela desconfiança relativa à manutenção do sigilo dos conteúdos que poderiam ser veiculados. As estagiárias enfatizaram a necessidade da participação de todas, o que finalmente ocorreu.

A presença das estagiárias serviu, a princípio, para estabelecer um campo mediado para as conselheiras desabafarem e denunciarem os percalços criados por uma ou outra na condução dos trabalhos. A expressão individual no espaço coletivo fez emergir uma realidade do trabalho de cunho predominantemente social.

Observaram-se, ao longo do processo, modificações na função que as conselheiras atribuíam à equipe interventora. Inicialmente, o espaço de intervenção consistiu em um dispositivo para catarse; posteriormente, transformou-se em um local de arbitragem para discussões de casos, reflexões e elaboração de dificuldades individuais e coletivas, além de propiciar a criação de dispositivos e estratégias de enfrentamento de litígios e de novas formas de operá-los: "o espaço no grupo se tornou muito importante pra nós. As fronteiras começaram a ser respeitadas, e isso está fazendo diferença nas relações entre nós... Nós já conversamos isso aqui muitas vezes" (C, décimo encontro).

Ademais, o espaço de intervenção foi sendo paulatinamente incorporado como elemento constitutivo da organização do trabalho das conselheiras, sem o qual o grupo teria dificuldade de funcionar, principalmente em ocasiões em que emergia alguma situação de confronto que exigia novo tipo de enfrentamento, negociação e replanejamento: "Hoje conversamos com todas para resolver os problemas de trabalho... Agradeço muito pela oportunidade dos encontros, eles foram mesmo fundamentais" (A, décimo sétimo encontro).

\section{Considerações finais}

As problemáticas concernentes à atuação do CT estudado coincidem com aquelas apresentadas na literatura pesquisada e que foram relacionadas na introdução deste trabalho. Quando encenados por personagens visíveis, e mais ainda quando vivenciados, os acontecimentos na dinâmica cotidiana de trabalho de um conselheiro se apresentam de tal forma imbricados e carregados de apelos emocionais tão intensos que exigem um constante trabalho de elaboração para que esse ator possa, para cada um dos muitos eventos vivenciados, oferecer respostas com um mínimo de clareza. O trabalho de elaboração exige distanciamento físico e tempo, elementos com os quais os conselheiros raramente podem contar.

O CT ainda pode se ver envolvido em engrenagens burocráticas e jogos políticos locais que emperram suas atividades. Este 
trabalho evidenciou também que o CT é, por vezes, tratado como um instrumento - e o conselheiro um mero operador - a serviço de um juízo modulado na vontade própria de alguns atores sociais. Tal posicionamento revela um julgamento de utilidade, baseado em uma visão clientelista da parte dos usuários, o que demonstra alienação dos dispositivos simbólicos que devem regular e reger não só a ação do demandante mas também o juízo do conselheiro tutelar.

A pressão no cotidiano de trabalho de um CT pode se lhe apresentar mais ou menos intensa, dependendo do grau de familiaridade que os componentes do quadro de conselheiros têm entre si e, sobretudo, das atividades que deve desenvolver. A principal fonte de sofrimento relatada derivou da intersubjetividade das componentes do CT. O sofrimento oriundo da interação entre as conselheiras pode ser atribuído também ao primeiro ano de gestão, quando ainda não se desenvolveram nem a inteligência prática para interagir com prontidão e precisão com os modos operatórios cotidianos de um CT nem a coordenação de ações necessária à efetivação e à eficácia do trabalho.

Assim, o primeiro ano de gestão de um quadro de conselheiras pode se mostrar carente de uma mediação que favoreça o intercâmbio em espaço coletivo, onde se possam também construir modos operatórios para tornar o trabalho fonte de desenvolvimento das subjetividades participantes. As estagiárias conseguiram, ao longo do processo, angariar a confiança das conselheiras e, mediante uma condução que se mostrou facilitadora, possibilitar algum nível de retificação subjetiva necessária ao empenho no embate com questões relativas à realidade do trabalho. $\mathrm{A}$ maior contribuição do trabalho psicológico realizado pode ser atribuída à criação de um espaço de relativa confiança no qual cada conselheira pôde se expressar, refletir a respeito do seu fazer, compartilhar dificuldades e procurar subsídios na troca com as demais a fim de se mobilizar para a ação com maior clareza.

Em avaliação final do estágio, as estagiárias consideraram que, do ponto de vista do ensino-aprendizagem, a introdução do triângulo da clínica do trabalho como referência orientadora facilitou a ação diagnóstica, a interpretação dos eventos e o manejo dos acontecimentos no setting. Por outro lado, pergunta-se: essa operação não teria restringido a percepção, pelas estagiárias, de outros fenômenos que pudessem ter emergido durante os encontros? Discutiramse, ainda, os modos operatórios da clínica realizada, os quais sofreram uma adaptação daquela originalmente proposta por Dejours e que resultou em uma prática denominada clínica focal do trabalho.

Concluindo, haja vista a escassez de investigações a respeito do CT, as autoras observam a necessidade de estudos acerca do assunto, seja em relação aos modos operatórios dos conselheiros, seja no que se refere às configurações de contextos sociais, gerais ou locais, que engendram, determinam ou constituem efeitos das ações de Conselhos Tutelares. 


\section{Norida Teotônio de Castro}

Doutora em Comunicação e Semiótica pela Pontifícia Universidade Católica de São Paulo, São Paulo - SP Brasil.

\section{Ana Helena Fernandes Toledo}

Especialista em Cinesiologia Psicológica - Integração Psicofísica/Instituto Sedes Sapientiae, Pouso Alegre, Minas Gerais - MG - Brasil.

E-mail: anahelenatoledo@globo.com.br

\section{Ana Maria Nunes Andery}

Graduada em Psicologia, Pouso Alegre, Minas Gerais - MG - Brasil.

E-mail: anandery@gmail.com

\section{Endereço para correspondência:}

Universidade do Vale do Sapucaí Secretaria de Pós-Graduação Av. Pref. Tuany Toledo, 470

Pouso Alegre, Minas Gerais - Brasil CEP 37 550-000.

E-mail: norida@uol.com.br

Recebido 4/6/2009, 1aㅡ Reformulação 24/5/2010, Aprovado 4/7/2010.

\section{Referências}

Abrahão, J. I., \& Torres, C. C. (2004). Entre a organização do trabalho e o sofrimento: o papel da mediação da atividade. Produção, 14(3), 67-76. Recuperado em 10 de abril de 2009, de http://www.scielo.br/pdf/csp/v18n5/10988.pdf

Andrade, A. N., \& Novo, H. A. (2004). Conselho Tutelar: possibilidade de exercício da cidadania. In L. Souza \& Z. Trindade (Eds.), Violência e exclusão: convivendo com paradoxos (pp. 119-131). São Paulo: Casa do Psicólogo.

Bleger, J. (1984). Psico-higiene e psicologia institucional. Porto Alegre: Artes Médicas.

Brant, L. C., \& Ninayo-Gomes, C. (2004). A transformação do sofrimento em adoecimento: do nascimento da clínica à psicodinâmica do trabalho. Rio de Janeiro: Escola Nacional de Saúde Pública.

Dejours, C. (1997). O fator humano. Rio de Janeiro: Fundação Getúlio Vargas.

Dejours, C. (1998). A loucura do trabalho: estudo de psicopatologia do trabalho (5a ed. rev. e ampl.). São Paulo: Cortez.

Dejours, C. (2004a). Análise psicodinâmica das situações de trabalho e sociologia da linguagem. In S. Lancman \& L. I. Sznelwar (Eds.), Christophe Dejours: da psicopatologia à psicodinâmica do trabalho (pp. 197-241). Rio de Janeiro: Fiocruz.

Dejours, C. (2004b). Da psicopatologia à psicodinâmica do trabalho. In S. Lancman \& L. I. Sznelwar, (Eds.), Christophe Dejours: da psicopatologia à psicodinâmica do trabalho (pp. 47-103). Rio de Janeiro: Fiocruz.

Dejours, C. (2004c). Entre sofrimento e reapropriação. In S. Lancman \& L. I. Sznelwar (Eds.), Christophe Dejours: da psicopatologia à psicodinâmica do trabalho (pp. 303-316). Rio de Janeiro: Fiocruz.

Dejours, C. (2004d). A metodologia em psicodinâmica do trabalho. In S. Lancman, \& L. I. Sznelwar (Eds.), Christophe Dejours: da psicopatologia à psicodinâmica do trabalho (pp. 105-126). Rio de Janeiro: Fiocruz.
Dejours, C. (2004e). Subjetividade, trabalho e ação. Produção, 14(03), 27-34. Recuperado em 20 de março de 2009, de http:// www.scielo.br/scielo.php?script=sci_arttext\&pid=S0103$65132004000300004 \&$ lng $=$ pt\&nrm $=$ iso

Dejours, C., \& Cardoso, M. R. (2001). Christophe Dejours: entrevista. Agora, 4(2), 89-94. Recuperado em 10 de abril de 2009, de http://www.scielo.br/pdf/agora/v4n2/v4n2a07.pdf

Frizzo, K. R., \& Sarriera, J. C. (2005). O Conselho Tutelar e a rede social na infância. Psicologia USP, 16(4), 198-209.

Frizzo, K. R., \& Sarriera, J. C. (2006). Práticas sociais com crianças e adolescentes: o impacto dos conselheiros tutelares. Psicologia: Ciência e Profissão, 26(2), 175-196.

Heloani, R., \& Lancman, S. (2004). Psicodinâmica do trabalho: o método clínico de intervenção e investigação. Produção, 14(3), 077-086.

Lacan, J. (1999). O seminário 5: as formações do inconsciente. Rio de Janeiro: Jorge Zahar.

Loureiro, S. R., \& Milani, R. G. (2008). Famílias e violência doméstica: condições psicossociais pós ações do Conselho Tutelar. Psicologia: Ciência e Profissão, 28(1), 50-67.

Molinier, P. (2004). Psicodinâmica do trabalho e relações sociais de sexo: um itinerário interdisciplinar: 1988-2002. Produção, 14(3), 14-26.

Prefeitura Municipal. Secretaria de Ação Comunitária e Cidadania. (1999). Sem dúvidas: Estatuto da Criança e do Adolescente. Santos, SP: Autor.

Sato, L. (2002) Prevenção de agravos à saúde do trabalhador: replanejando o trabalho através das negociações cotidianas. Cadernos de Saúde Pública, 18(5), 1147-1157. Recuperado em 10 de abril de 2009, de http://www.scielo.br/pdf/csp/ v18n5/10988.pdf

Souza, M. P. R., Teixeira, D. C., \& Silva, M. C. Y. G. (2003) Conselho Tutelar: um novo instrumento social contra o fracasso escolar? Psicologia em Estudo, 8(2), 71-82. 